This item was submitted to Loughborough's Research Repository by the author.

Items in Figshare are protected by copyright, with all rights reserved, unless otherwise indicated.

\title{
Parenting in youth sport: a position paper on parenting expertise
}

PLEASE CITE THE PUBLISHED VERSION

http://dx.doi.org/10.1016/j.psychsport.2014.03.001

\section{PUBLISHER}

(c) Elsevier

\section{VERSION}

AM (Accepted Manuscript)

\section{PUBLISHER STATEMENT}

This work is made available according to the conditions of the Creative Commons Attribution-NonCommercialNoDerivatives 4.0 International (CC BY-NC-ND 4.0) licence. Full details of this licence are available at: https://creativecommons.org/licenses/by-nc-nd/4.0/

\section{LICENCE}

CC BY-NC-ND 4.0

\section{REPOSITORY RECORD}

Harwood, Chris G., and Camilla J. Knight. 2019. "Parenting in Youth Sport: A Position Paper on Parenting Expertise". figshare. https://hdl.handle.net/2134/16958. 
1 RUNNING HEAD: EXPERTISE IN SPORT PARENTING

2

3

4

5

6

7

8

9

10

11

Parenting in youth sport: A position paper on parenting expertise 


\section{EXPERTISE IN SPORT PARENTING}

2 Objectives: In line with the aims of this special issue, the purpose of this paper is to forward

3 a position on the concept of sport parenting expertise through the presentation of six key

4 postulates.

5 Design: Literature review and position statement.

6 Method: By adopting methods associated with an academic position paper, a statement is

7 presented that we believe encapsulates sport parenting expertise. Six key postulates of

8 parenting expertise, formulated from critically reviewing and interpreting relevant literature,

9 are then presented.

10 Results: We propose that sport parenting expertise is dependent on the degree to which 11 parents demonstrate a range of competencies; namely that parents, (a) select appropriate appropriate parenting styles, (c) manage the emotional demands of competitions, (d) foster

14 healthy relationships with significant others, (e) manage organizational and developmental

15 demands associated with sport participation, and, (f) adapt their involvement to different 16 stages of their child's athletic career.

17 Conclusion: Expertise in sport parenting requires parents to develop knowledge and utilize a range of intrapersonal, interpersonal, and organizational skills in order to support their child, manage themselves, and operate effectively in the wider youth sport environment.

20 Recommendations for applied researchers to further investigate these postulates and

21 substantiate the components of sport parenting expertise are offered.

Key Words: Sport Parenting, Expertise, Youth Sport, Talent Development, 


\section{EXPERTISE IN SPORT PARENTING}

Parenting in youth sport: A position paper on parenting expertise Over the past decade, scientific investigations of youth sport have been largely informed by two differing yet complimentary research strands that champion the role of sport within important social, health, economic, and commercial outcomes. The first strand focuses on the processes of talent development in sport. Such research is often driven by the acknowledgement that professional, international, and Olympic success leads to substantial economic rewards and pride for the athlete and the country he or she is representing (Martindale, Collins, \& Abraham, 2007). With such a focus on results in the elite sport industry, an understanding of the mechanisms behind successful talent development has represented a fertile and critical challenge for researchers (see Bailey \& Morley, 2006; Henriksen, Stambulova, \& Roessler, 2010; MacNamara, Button \& Collins, 2010a, 2010b). The second of these strands focuses on youth sport as a vehicle for positive youth development. That is, research focuses on experiential learning of psychosocial competencies and life skills through sport that enable young people to effectively manage adolescent-toadult transitions and positively contribute to society (Dworkin, Larson, \& Hansen, 2003; Fraser-Thomas, Côté, \& Deakin, 2005; Holt, 2008). An important and additional element to this strand is the role of youth sport participation in physical activity and health outcomes, beyond the development of cognitive, social, and emotional assets (Benson, Leffert, Scales, \& Blyth, 1998; Johnston, Harwood, \& Minniti, 2013).

Although the fundamental goals of each research strand bear divergence on philosophical grounds, there is congruence with respect to the role significant others play in facilitating both 'talent’ and 'positive youth’ development objectives (Côté, 1999; Holt \& Dunn, 2004). Namely, the quality of the environment shaping the child-athlete through appropriate adult role models and supportive relationships is perceived as vital to the growth of psychosocial attributes relevant to each goal (Bronfenbrenner, 1999; Fraser-Thomas, et al., 


\section{EXPERTISE IN SPORT PARENTING}

1 2005; MacNamara et al., 2010b). Two of the main adult protagonists in these fields of

2 research are coaches and parents, and there is burgeoning literature devoted to the roles,

3 experiences, and behaviors of these significant others (e.g., Camiré, Forneris, Trudel, \&

4 Bernard, 2001; Côté, 1999; Vella, Oades, \& Crowe, 2011; Wolfenden \& Holt, 2005).

Given the importance of coaches in the lives of young athletes, it is unsurprising that

6 extensive research attention has been given to understanding the components, development,

7 and outcomes of coaching expertise (e.g., Côté \& Gilbert, 2009; Horton, Baker, \& Deakin,

8 2005; Portrac, Jones, \& Armour, 2002). Although the academic study of sport parenting is

9 less extensive and historically established than sport coaching, the literature reflecting

10 parental influence and involvement in youth sport has grown substantially in recent years.

11 Researchers have not only explored the perceptions and consequences of sport parental behaviors (e.g., Babkes \& Weiss, 1999; Bois, Lalanne, \& Delforge, 2009; Leff \& Hoyle, 1995), but have also begun to demonstrate the complexities and challenges of being a sport parent (Holt, Tamminen, Black, Sehn, \& Wall 2008; Knight \& Holt, 2013c).

Nevertheless, a potential limitation of the literature on sport parents is the absence of a specific focus on the notion of parenting expertise. Over the last decade, through a collection of separate studies, scholarly knowledge has been shared on the behavioral preferences of athletes regarding their parents at competitions (Knight, Boden, \& Holt, 2010; Knight, Neely, \& Holt, 2011; Omli \& LaVoi, 2011), coaches perceptions of positive and negative parenting practices (e.g., Gould, Lauer, Rolo, Jannes, \& Pennisi, 2006, 2008), and adaptive versus less adaptive parenting styles and practices (e.g., Holt, Tamminen, Black, Mandigo, \& Fox, 2009; Lauer, Gould, Roman, \& Pierce, 2010a, 2010b; Sapieja, Dunn, \& Holt, 2011). Researchers have also established lines of research into parents’ experiences, stressors, and emotions associated with parenting in youth sport (Dorsch, Smith, \& 


\section{EXPERTISE IN SPORT PARENTING}

1 Fifer, 2008). This body of research has separately illustrated several pertinent components of

2 parenting in sport. However, researchers have not taken an integrated approach that

3 synthesizes parental strengths and configures the concept of sport parenting expertise as a

4 totality. Therefore, in line with the literature examining coaching expertise, the purpose of

5 this paper is to forward a preliminary position on the concept of sport parenting ${ }^{1}$ expertise.

$6 \quad$ In keeping with the process of an academic position paper (see Tucker, Derelian, \&

7 Rouner, 1997), we will first present a statement that we believe encapsulates sport parenting

8 expertise. Then we will build the case for our position by critically reviewing and interpreting

9 relevant literature, and by applying our academic and professional experience in youth sport.

10 Literature on parenting in sport was identified through a keyword and abstract search using

11 the terms sport or athletic and words relating to parenting, such as parent, family, mother,

12 father, son, daughter, stepfather, stepmother, stepparent ${ }^{2}$ in Scopus, PsycInfo, and

13 SportDiscus. The search, limited to journal articles and dissertations written in English,

14 returned 1996 articles in Scopus, 3114 articles in PsychInfo, and 1442 articles in

15 SportDiscus. All article titles were reviewed and unrelated articles were discarded, leaving 95

16 articles in Scopus, 239 in Psychinfo, and 256 in SportDiscus. The abstracts of remaining

17 articles were then reviewed and any duplicate or unrelated articles were removed. The

18 remaining articles were used to guide the development of the subsequent position statement.

19 Using a similar method to Côté, Lidor, and Hackfort (2009) our case will be made by

20 proposing six postulates that we believe represent the components of parenting expertise and

21 that are based on our interpretations of the available literature. Within each postulate, and conventional to position statement methodology, we will appraise the strength of the supporting literature and propose recommendations for further research where our evidence is

24 weaker. Finally, we will summarize the key theoretical considerations by drawing together

\footnotetext{
${ }^{1}$ Parent/parenting is used to refer to parents, legal guardians and primary caregivers

${ }^{2}$ Boolen search was conducted for all terms
} 


\section{EXPERTISE IN SPORT PARENTING}

1 the postulates to provide a broader overview of sport parenting expertise and will highlight

2 the implications of our position for practitioners, organizations, and researchers interested in

3 this area of study.

\section{Sport Parenting Expertise}

We propose expertise in sport parenting is demonstrated through parental involvement that increases the chances for children to achieve their sporting potential, have a positive psychosocial experience, and develop a range of positive developmental outcomes.

Such involvement requires parents to develop specific intrapersonal, interpersonal, and organizational skills that are demonstrated through fulfillment of the following six postulates.

\section{Postulate No 1: Parents select the appropriate sporting opportunities for their child and}

\section{provide necessary types of social support}

We believe a primary component of sport parenting expertise is a parent's ability to provide their child with appropriate opportunities in sport and offer the types of support that allows children to optimize their enjoyment and performance. As one of three key sport parenting roles ascribed by Fredricks and Eccles (2004), there is extensive evidence of how parents serve as providers of a young athlete’s experience (e.g., Baxter-Jones \& Maffuli, 2003; Bloom, 1985; Côté, 1999; Hellstedt, 1990; Rees \& Hardy, 2000; Wolfenden \& Holt, 2005). However, we contend that parents with greater expertise not only support children's opportunities, but also select the sporting opportunities that are appropriate for their children.

Selection of correct opportunities. Our contention is informed by studies within the talent development literature (e.g., Bloom, 1985; Côté, 1999; Wuerth, Lee, \& Alfermann, 2004; Wylleman \& Lavallee, 2004), which have indicated that children progress through different stages as they seek to become elite performers, and these stages are characterized by different factors. The extent to which parents provide children with opportunities that align with these different stages is likely to influence the extent to which children can achieve their 


\section{EXPERTISE IN SPORT PARENTING}

1 sporting potential (cf., Bloom, 1985, Côté, 1999). The appropriateness of opportunities

2 children are afforded can also influence the longevity of children's sporting involvement,

3 their psychosocial experiences, and the chances of experiencing injury (Côté, Baker, \&

4 Abernethy, 2007; Fraser-Thomas \& Côté, 2009; Fraser-Thomas, Côté, \& Deakin, 2008).

5 For example, research has indicated that children who participate in a range of fun and

6 enjoyable sporting activities early in their career (rather than specialize within one sport or

7 commit to structured training and extensive competition) are likely to have more positive

8 experiences and better developmental outcomes (Côté et al., 2007; Côté \& Hay, 2002;

9 Strachan, Côté, \& Deakin, 2009). Similarly, studies with elite performers consistently

10 illustrate the value of sampling a variety of sports during their formative sporting years (e.g.,

11 Bloom, 1985; Côté, 1999; Soberlak \& Côté, 2003; Wuerth et al., 2004). Thus, by interpreting

12 the available literature, there is growing scientific support to propose that during children's

13 initial sporting experiences expertise in sport parenting is displayed when parents initiate

14 opportunities for their child to participate in a range of activities, with limited competition

15 and a focus on learning through play.

16 As children progress it is apparent that those children seeking to achieve an elite level begin to decrease their range of activities and focus more specifically on one or two sports (Baker, Côté, \& Abernethy, 2003; Bloom, 1985; Côté, 1999; Soberlak \& Côté, 2003). In accordance with this specialization, children increase their involvement in deliberate practice and require increasing technical and tactical information from appropriate coaches (Bloom, 1985; Côté et al., 2007). As such, a key responsibility for parents is to seek out more appropriate and higher-level competitive experiences for their children while ensuring access to professionally structured coaching and training programs. However, not all children (or

24 their parents) will have aspirations to achieve an elite level in sport (Knight \& Holt, 2014).

25 Thus, specializing in one or two sports might not be appropriate or desired (Côté \& Hay, 


\section{EXPERTISE IN SPORT PARENTING}

1 2002). Instead, such children might seek to follow a recreational path and continue to

2 participate in a range of sports and activities (Côté et al., 2007). In such instances, parental

3 provision of the appropriate opportunity is likely to be reflected in continued access to

4 multiple, fun-focused activities.

5 Given the various outcomes (e.g., achieve an elite status; experience a range of sports)

6 children and parents might desire from youth sport, it seems a critical aspect of parenting

7 expertise is a parent's understanding of what their child wants to achieve through

8 participation and what they are hoping their child will achieve. The importance of the

9 interaction between parental self-awareness and awareness of their child's goals was

10 highlighted in a recent study conducted by Knight and Holt (2014). Knight and Holt

11 constructed a grounded theory of optimal parental involvement in junior tennis. Critical to

12 achieving optimal parental involvement was parents and children having shared and

13 communicated goals. That is, for parents to optimize their involvement in their child's sport

14 they must know what they and their child are seeking to achieve (Stein, Raedeke \& Glenn,

15 1999). Although further research is required on this particular process, we would suggest

16 expertise is achieved and displayed when parents have some knowledge of the literature on

17 talent development and possess the intrapersonal (e.g., self-awareness) and interpersonal

18 (e.g., listening) skills required to understand personal and child-centered needs, and adapt

19 personal goals in favor of what is valued by their child (see Burleson, Delia \& Applegate, 20 1995).

21 Appropriate types of social support. Returning to the second element of this postulate, there is a substantial body of evidence reinforcing the manners in which sport

23 parents offer appropriate social support (and avoid pressuring behaviors) to optimize their

24 child's opportunities, experience, and development (e.g., Gould et al., 2006, 2008; Lauer et 25 al., 2010a, 2010b; Holt \& Dunn, 2004; Wolfenden \& Holt, 2005). For example, Leff and 


\section{EXPERTISE IN SPORT PARENTING}

1 Hoyle (1995, Hoyle \& Leff, 1997) conducted two studies examining young athletes’

2 perceptions of parental support, pressure, and involvement. In their first study, 154 junior

3 tennis players reported on their parents' involvement in tennis, their enjoyment of tennis, and

4 self-esteem. Results illustrated that perceived support from mother and father was positively

5 correlated with enjoyment and global and tennis self-esteem. These findings were supported

6 in their follow-up study, with additional positive correlations between parental support and

7 both an objective measure of performance and the value children placed on tennis.

9 athletes achieve an elite status in sport (e.g., Baker, Horton, Robertson-Wilson, \& Wall, 10 2003; Côté, 1999; Holt \& Dunn, 2004). For example, Wolfenden and Holt (2005) conducted

11 interviews with three parent-player-coach triads to examine perceptions of talent

12 development in elite tennis. Data analysis revealed the importance of parents providing all

13 key forms of social support (Rees \& Hardy, 2000) to their child. Emotional support was

14 viewed as central to the parent-child relationship, particularly following tough matches or a

15 losing streak. Participants also discussed the necessity of parents' tangible support, a factor

16 that is often taken for granted, yet is a critical component to the youth sport experience (e.g.,

17 Baxter-Jones \& Maffuli., 2003; Kirk et al., 1997a, 1997b). Finally, the value of parents providing informational support through general advice, such as keeping tennis in perspective or discussing opportunities for combining tennis and schooling, was also highlighted.

Given the need for parental support in youth sport, we believe an additional characteristic of expertise is reflected in parents who proactively develop strategies to ensure they are able to appropriately attend to and support their children’s needs (Dorsch et al., 2009; Knight \& Holt, 2014). Knight and Holt (2013b) illustrated this use of support systems

24 in a study with parents of regional and national tennis players in the US. Parents were asked to discuss the strategies they used to support their tennis-playing children. Parents indicated 


\section{EXPERTISE IN SPORT PARENTING}

1 committing to self-education by devoting many hours to independently learning about their

2 child's sport, the psychology of tennis, and how to be a tennis parent. Parents also discussed

3 turning to their child's coach to receive emotional support, using other parents for

4 informational support, and sharing tasks with their spouse to reduce demands. Although more

5 specific research is needed on this topic, the process of parents having to gain sport parenting

6 specific knowledge and 'learning the trade' of sport parenting appears a logical and necessary

7 aspect of parenting expertise. Educating parents about the role of self-development and the

8 importance of accessing other support systems may reflect important induction material for

9 organizations that want to help parents to 'learn the trade' more effectively.

10 In sum, we would contend one of the primary characteristics of expertise in sport

11 parenting is the ability for parents to consider sporting opportunities in the best interests of their child, and to be able to provide support that complements the demands of training and competition experienced by children. There is generally strong evidence for this suggestion -

14 particularly with regards to the importance of parental support. Further research examining

15 the ways in which parents go about learning how to provide such support, particularly as

16 children progress in sport is warranted to further strengthen our confidence in this postulate.

Postulate no. 2: Parents understand and apply an authoritative or autonomy-supportive parenting style

We believe a parent's ability to create a healthy emotional climate for their child, through their application of specific parenting styles, is a pertinent component of sport

21 parenting expertise. Parenting style represents the broad manner in which parents interact with their child, reflective of the parent's values and expectations around appropriate parentchild interactions (Darling \& Steinberg, 1993). Research examining the relationship between parenting styles and child outcomes is extensive, including topics ranging from children's and adolescents academic achievement and competence (e.g., Spera, 2006), to depressive 


\section{EXPERTISE IN SPORT PARENTING}

1 symptoms (e.g., Milevsky, Schlechter, Netter, \& Keehn, 2006), and engagement in a variety

2 of health behaviors (Arredondo, Elder, Ayala, Campbell, Baquero, \& Duerksen, 2006;

3 O’Byrne, Haddock, \& Poston, 2002).

The majority of research has drawn on Baumrind's (1971) and Maccoby and Martin’s

5 (1983) classifications of parenting styles. Baumrind (1971) originally developed a three-fold

6 typology of parenting styles, labeled authoritative, authoritarian, and permissive. Maccoby

7 and Martin (1983) subsequently adapted this three-fold typology into four parenting styles.

8 These parenting styles were formed based on two dimensions of parenting behaviors:

9 acceptance/responsiveness, and demandingness/control. The four parenting styles based on

10 these dimensions were authoritarian (high in demandingness and low in responsiveness),

11 indulgent (high in responsiveness and low in control), neglectful (low in responsiveness and

12 low in control), and authoritative (high in both responsiveness and control). In general,

13 research examining parenting styles and health contexts, particularly in Western cultures, has

14 indicated more positive outcomes as a result of an authoritative parenting style (e.g.,

15 Arredondo et al., 2006; Schmitz, Lyle, Phillips, Murray, Birnbaum, \& Kubik, 2002).

16 However, there is research support indicating a permissive parenting style might be associated with more active children (Jago, Davison, Brockman, Page, Thompson, \& Fox, 2011; Hennessy, Hughes, Goldberg, Hyatt, \& Economos, 2010).

The concept of parenting style is relatively new to sport psychology research.

20 Nonetheless, those studies that have been conducted lend support to our contention that sport

21 parenting expertise is underpinned by the adoption of authoritative and/or autonomysupportive styles (Holt, et al., 2009; Juntumaa, Keskivaara \& Punamaki, 2005; Sapieja et al., 2011). For example, Juntumaa and colleagues (2005) conducted a study examining the

24 influence of parenting style on ice-hockey players' achievement strategies, their norm breaking behaviors, and satisfaction with hockey. Results illustrated that authoritative 


\section{EXPERTISE IN SPORT PARENTING}

1 parenting was associated with high levels of mastery oriented behavior, lower levels of norm-

2 breaking behavior, and enhanced satisfaction with hockey. In contrast, athletes from

3 authoritarian families were more likely to partake in norm-breaking behavior. In a more

4 recent cross sectional investigation, Sapieja et al. (2011) examined the influence of parenting

5 styles on perfectionistic orientations in adolescent male soccer players. Players categorized as

6 healthy perfectionists and non-perfectionists reported significantly higher perceptions of

7 maternal and paternal authoritativeness compared to unhealthy perfectionists.

Holt and colleagues (2009) illustrated the complexity of parenting styles and their

9 application within youth sport contexts in their qualitative study of parenting styles and

10 practices. A combination of season long observations of two junior soccer teams and

11 interviews with the players and 56 parents were used to identify the general parenting styles and practices adopted. In contrast to other studies, Holt et al. drew from Grolnick’s (2003) parenting styles based on the constructs of autonomy, competence, and relatedness contained within Self-Determination Theory (Deci \& Ryan, 1985). Grolnick argued parenting styles effect children's need satisfaction through their provision of structure, autonomy-supportive environments, and levels of involvement. With respect to the four alternative dimensions

17 (Maccoby \& Martin, 1983), an authoritative parenting style is closely aligned to appropriate structure, autonomy-support, and involvement (Gurland \& Grolnick, 2005). Holt et al. (2009) reported parents engaged in autonomy-supportive, controlling (i.e., authoritarian), or mixed parenting styles, with more positive types of parenting practices being associated with autonomy-supportive rather than controlling parenting styles. parents ensuring consistency between parenting styles. Although we have a growing body of evidence supporting a position that parents with greater expertise individually adopt 


\section{EXPERTISE IN SPORT PARENTING}

1 depend upon the spousal dynamic (in two-parent families). We would contend that a

2 precursor to the expertise of the 'father-mother' dynamic lies in their self-awareness of each

3 other's style and how differences could influence the emotional climate they co-create.

To summarize, we propose that one component of sport parenting expertise is a

5 parent's ability to understand these more optimal parenting styles and work separately or

6 together in applying an authoritative or autonomy- supportive style with their child.

7 However, as indicated, there is only a limited body of work in sport from which to draw this

8 conclusion. Additional evidence to support this postulate is required, particularly with

9 populations that reside outside of North America. Researchers are also encouraged to

10 investigate this postulate in order to inform the degree to which parenting styles and family

11 configuration influence a range of other psychosocial and performance-related factors (e.g., stress, self-regulation skills; confidence; leadership) in youth sport.

Postulate no. 3: Parents manage the emotional demands of competition and serve as emotionally intelligent role models for their child

$$
\text { The inherent caregiver and supervisory roles of parents, alongside children’s }
$$
dependency on transportation, mean parents are often a ubiquitous presence at youth sport competitions. Attending such competitions can be a highly emotional experience and one that many parents find challenging. We believe a characteristic of expertise is reflected in parents who possess the ability to manage the various emotional demands of competition.

Furthermore, this coping ability then serves as a precursor for parents to engage in emotionally intelligent interactions and role model practices around competitions that facilitate an optimal experience for their child (Knight \& Holt, 2014). Substantiating this postulate necessitates an appraisal of two related avenues of sport parent research: (a) research that has investigated parents' experiences of competition (Dorsch et al., 2009; Omli 


\section{EXPERTISE IN SPORT PARENTING}

1 Fifer, 2008), and (b) research that has explored parenting practices at, or related to, competitions (e.g., Bowker et al., 2009; Holt et al., 2008; Knight et al., 2011).

of emotions at competitions related to a range of stressors that can arise in the competition setting. For example, Table 1 displays the competition stressors reported by 22 parents of high-level junior tennis players interviewed by Harwood and Knight (2009b). Important to note here is these stressors are reported by parents across the three developmental stages (sampling, specializing, and investment), and they illustrate the range of sources (e.g. own child's emotions; opponent behavior; other parents interference) and time points (before, during and after competition) that contextualize the stress experience for the parent.

While Harwood and Knight's (2009b) study did not target the specific emotions reported by parents as a result of each stressor, Omli and LaVoi (2012) specifically sought to understand parents' experiences of anger in youth sport competitions. Through an openended survey, 516 parents of children aged 5-19 years recalled instances of experiencing anger at competitions. The core stimuli for such anger included perceived unjust behaviors from coaches and referees, uncaring behaviors from coaches, athletes, and other parents, and perceptions of referee and coach incompetence. We believe a parent's ability to cope with anger represents an important component of sport parenting expertise given the detrimental consequences it can have for children, opponents, other parents and officials (cf., Knight \& Holt, 2013a; Omli \& LaVoi, 2009). Beyond the ability to cope with anger, research has also illustrated how parents may have to master a range of other emotions at competitions. A recurring example is the reported disappointment and worry parents empathically feel or share with their child when they see their child is disappointed or upset (e.g., Dorsch et al., 2009; Holt et al., 2008; Knight \& Holt, 


\section{EXPERTISE IN SPORT PARENTING}

1 2013a; Wiersma \& Fifer, 2008). Parents have cited feeling embarrassed if they perceive their

2 children are underperforming or behaving poorly (Dorsch et al., 2009; Harwood \& Knight,

3 2009a, 2009b). In Harwood and Knight’s (2009b) study, the inappropriateness of interrupting

4 a competition and taking resolute action with their child rendered parents as helpless

5 bystanders to their child's emotions and mistakes.

6 Given this existing literature, we propose that a parent's ability to manage these

7 emotional demands of competition will impact upon their personal enjoyment, quality of

8 experience, and engagement in optimal support practices (cf. Knight \& Holt, 2013a).

9 Unfortunately, few studies have devoted specific attention to the strategies parents use to

10 manage their emotions at competitions. Grass roots sport parents within Dorsch and

11 colleagues' (2009) study discussed their use of mirroring strategies - whereby they altered

12 their emotions or reactions based on reading their child's emotions. Other strategies

13 forwarded by existing literature include assigning specific tasks to parents at competitions,

14 increasing opportunities for parents to socialize, and direct education to parents on the values

15 and benefits of youth sport beyond an emphasis on competition outcomes (e.g., Harwood \&

16 Knight, 2009a; Gould et al., 2008). Although we believe the development of strategies to

17 manage emotions is an indicative component of expertise, further coping-based research is

18 required to understand precisely how parents gain or develop these strategies.

Emotionally intelligent interactions and role model practices. When parents do

appropriately manage the competition experience, we deem they have the potential to excel at

21 a range of interactions and practices that serve to enhance the experience for their child,

22 themselves, and other stakeholders (e.g., other parents, officials, coaches). There is an

23 extensive body of evidence that informs scholars and practitioners of exactly what parents are

24 capable of doing or could be doing at competitions. For example, observational studies of

25 parental involvement at youth competitions have indicated that approximately two-thirds of 


\section{EXPERTISE IN SPORT PARENTING}

1 parents' behaviors are appropriate or positive, while approximately one third of behaviors are

2 negative or inappropriate (Bowker et al., 2006; Kidman, McKenzie, \& McKenzie, 1999).

3 Through extensive observations of parents in youth soccer matches, interviews, and audio-

4 diaries, Holt and colleagues (2008) developed a grounded theory of parental involvement at

5 youth sport competitions. Their findings illustrated how parents' verbal reactions at matches

6 varied along a continuum from praise and encouragement, performance contingent feedback,

7 instruction, striking a balance, negative comments, and derogatory comments. In support of

8 our contention regarding emotional demands, Holt and colleagues suggested the nature of

9 parental reactions were influenced by parents' empathy with their child, the emotional

10 intensity of the game, and parents' perceived knowledge and experience of sport. We believe

11 that parents with greater expertise operate along the continuum from praise and encouragement to performance-contingent feedback, halting before or when they reach instruction. Indeed, a number of recent studies examining children’s preferences for parental involvement at competition provide direct support to substantiate our contention.

Knight and colleagues (2010) examined junior tennis players’ preferences for parental involvement at tournaments through focus groups involving 42 adolescent tennis players from Canada. Players offered a basic blueprint for the behaviors they most desired from their parents, under a general umbrella of providing support without being pressuring. To achieve this, participants indicated parents should avoid providing technical or tactical advice, ensure comments focus on the players' effort and attitude rather than performance or outcome,

21 provide practical advice to help players prepare and recover from matches, respect tennis etiquette, and match nonverbal behaviors with supportive comments. Subsequently, Knight et al. (2011) conducted a follow-up study with 36 female adolescent athletes from team sports.

24 This study provided support for the original findings in addition to athletes offering specific temporal preferences for behaviors before, during, and after competitions. This study also 


\section{EXPERTISE IN SPORT PARENTING}

1 provided a clear indication of the need for specific behaviors related to the whole team,

2 highlighting a potential difference between parenting in individual and team sports.

Omli and Wiese-Bjornstal (2011) further substantiated the components of behavior

4 young athletes most liked from their parents. Athletes' responses were organized around

5 three different 'types’ of parents: Supportive parents, demanding coach, and crazed fan.

6 Supportive parents displayed behaviors including cheering and providing encouragement

7 during and after events, providing praise and displaying empathy for other teams, and calling

8 to officials when they were trying to protect a child from injury. These behaviors were

9 consistently identified as positive or wanted during competitions. The demanding coach

10 displayed behaviors that were generally disliked but tolerated by children, such as providing

11 instruction during the game, giving advice during breaks in the game, and providing critical encouragement. The crazed fan engaged in behaviors children disliked, including arguing with coaches and officials, blaming officials for losses, being derogatory towards opposing teams, and fanatical cheering. These behaviors were disliked by children.

We believe these aforementioned studies help to build the profile of a parent who is emotionally intelligent in his or her interactions with their child and with the competition environment. They understand their child’s emotional needs, appreciate values such as effort, sportpersonship, independence, honesty, composure, and constructive feedback, and behave in a manner that role models these values to their child. In this way, parents fulfil the role of interpreter and role model, in addition to provider, as proposed by Fredricks and Eccles

21 (2004) (See Table 2 for examples of parental behaviors relative to these roles). That is, parents' understanding of their own and their child's emotions will influence the extent to which they are able to helpfully interpret their child’s sporting experience. Similarly, if parents are able to maintain control of their own emotions and behave in manners appropriate for the sport (e.g., respect sporting etiquettes), this is likely to be replicated by children 


\section{EXPERTISE IN SPORT PARENTING}

1 (Babkes \& Weiss, 1999). In sum, we encourage scholars to further explore the concept of

2 parental emotional intelligence, how it influences behaviors at competitions, and translates

3 into a parent's 'interpreter' and 'role model' roles with young athletes.

4 Postulate no. 4: Parents foster and maintain healthy relationships with significant

5 others in the youth sport environment

6 When children participate in sport they interact with a range of people including other

7 children and parents, coaches, officials, and organizers. Consequently, parents also interact

8 with such people and we believe a parent's skills in developing and maintaining relationships

9 with these key stakeholders exert a significant influence on the overall quality of the youth

10 sport environment. Several research studies speak to the importance of parental relationships

11 with children, coaches, and other parents to support this postulate. Firstly, Ullrich-French and

12 Smith (2006) illustrated how youth soccer players' perceptions of the quality of relationship

13 with their mother and father were associated with a range of positive psychological

14 outcomes. Five dimensions representing relationship quality were reported on by players.

15 These were self-esteem enhancement and supportiveness, loyalty and intimacy, things in

16 common, companionship and play, and conflict resolution. Results revealed how higher quality father-child and mother-child relationships both predicted higher levels of player enjoyment, perceived competence, self-determined motivation, and lower levels of stress. Jowett and Timson-Katchis (2005) illustrated how parents, as a 'psychologicallysignificant network member' (p. 267) within the 'coach-athlete-parent triad,' facilitated an effective coach-athlete relationship for their child in a number of ways. For example, parents created opportunities for frequent communications and working exchanges with the coach, both giving and receiving regular information about their child's specific needs. Parents also assisted coaches by helping their children to resolve conflicts or frustrations that occasionally arose with the coach, guiding their child towards alternative interpretations by providing 


\section{EXPERTISE IN SPORT PARENTING}

1 emotional support. These relational skills were reported to assist the dyadic partnership

2 between coach and athlete, with subsequent research reinforcing how positive parent-coach

3 relationships are characterized by trust and understanding, and a mutual appreciation of the

4 demands each party is facing (Smoll, Cumming \& Smith, 2011; Wolfenden \& Holt, 2005).

Readers interested in the composition of effective parent-coach relationships are

6 encouraged to consider Smoll and colleagues (2011) propositions for creating harmonious

7 parent-coach relations that was followed by ten invited commentaries from youth sport

8 psychologists in a special issue of the International Journal of Sports Science and Coaching.

9 In addition, Knight and Harwood's (2009) study of parent-initiated coaching stress offers

10 insights into how parents can minimize the stress for coaches through their interactions and

11 behavior. From this literature, we contend that greater expertise is achieved by parents who are able to share their child with the coach, accept the coach's authority, and do not undermine his or her leadership, particularly in front of the athlete. These parents support the coach with relevant input but they allow the coach to drive the pace of learning and development without interference. Such parents also take responsibility for the behavior of their child, and support the coach on reinforcing appropriate attitudes and behaviors in training and competition (cf. Gould et al., 2006, 2008). Alongside a keenness to develop their knowledge of the sport from the coach, parents with expertise will also listen to the coach about issues such as scheduling so their child benefits from an appropriate and periodized program of training, competition, rest and recovery.

Beyond parent-coach relationships, we contend that expertise in sport parenting extends to the development of healthy relationships with other parents encountered in youth sport (Knight \& Holt, 2013a, 2013b). The potential for angry interactions to occur between parents (and other individuals) at competitions has already been noted and serves as a 


\section{EXPERTISE IN SPORT PARENTING}

1 interference, shouting, cheating, and derogatory comments have all been cited as stressors for

2 parents (Harwood \& Knight, 2009a, 2009b), which inevitably damage relationships between

3 parents and can negatively affect children's experiences and relationships with other children.

Research has highlighted the value of parents being friends with or supportive of other parents (Knight \& Holt, 2013a, 2013b), as well as benefitting from opportunities to socialize with other parents (Dorsch et al., 2009; Wiersma \& Fifer, 2008). Additionally, other parents have served as important sources of information (Knight \& Holt, 2013b) and can potentially distract parents from the anxiety they experience within the sporting environment (Knight \& Holt, 2013a). However, although we believe that an aspect of parenting expertise is to foster and maintain healthy parent-parent relationships, there is very little direct research on the composition, process, skills, and challenges of maintaining such a relationship.

In terms of self-care and management, given the time and organizational demands placed on parents, we believe it is important for parents to recognize the value of creating a social network where they can feel part of a sporting community. Through such a community, parents’ own social needs may be partly met at training and competitions (Knight \& Holt, 2013a). We also feel that more astute parents recognize that sport provides their child with opportunities to fulfill relatedness needs (Deci \& Ryan, 1985), building lifelong friendships and peer relationships. Positive relational skills with other parents in terms of resolving between-child and between-parent conflicts may be critical in maintaining the psychological health of a youth sport friendship.

In conclusion, we believe an understanding from parents of the role they play in creating healthy youth sport environments is a necessary component of sport parenting expertise. We propose that parents with this greater expertise are aware that developing and maintaining multiple healthy relationships is beneficial for their child, for coaches, other parents, and children, and also beneficial for themselves. Although we have cited and 


\section{EXPERTISE IN SPORT PARENTING}

1 discussed research to support this postulate, we believe there is the opportunity for more

2 sophisticated dyadic research to further inform our contention. Specifically, the development

3 and maintenance of parent-parent relationships, including the relational skills and strategies

4 employed by parents in team and individual sports, would be a rich and worthy topic for

5 investigation.

6 Postulate no. 5: Parents manage the organizational and developmental demands placed

7 on them as stakeholders in youth sport

The closing points within the previous postulate highlight the bi-directional nature of youth sport, with children's involvement and the youth sport environment serving to socialize and influence parents and their way of life (Dorsch et al., 2009; Holt et al., 2009). Sport parents are required to manage the emotional demands of competition (e.g., competition stressors), but expertise also likely extends to handling many other demands. Over the past decade, researchers have made the conceptual distinction between athlete and coach stressors linked specifically to competition and competitive performance (i.e., competitive stress) with the stressors associated primarily and directly with the organizational aspects of sport (i.e., organizational stress; Hanton \& Fletcher, 2005; Woodman \& Hardy, 2001). This conceptual distinction also applies to sport parents, particularly in youth sport.

Although a plethora of research has considered the influence of parents on youth sport participants, recent studies have taken a more parent-centric stance and examined the effects of youth sport on parents themselves (Harwood \& Knight, 2009a, 2009b; Lally \& Kerr, 2008;

21 Wiersma \& Fifer, 2008). From this literature we recognize sport parents are faced with demands related to organizational factors and processes that can deeply affect their personal and family life, as well as demands related to their child's ongoing athletic development,

24 educational decisions, changing support needs, and career transitions. Therefore, we contend 


\section{EXPERTISE IN SPORT PARENTING}

1 that a characteristic of parenting expertise is a parent's ability to cope with these demands by

2 means of a variety of intrapersonal, interpersonal and organizational skills and strategies.

Scientific support for our proposal of organizational and developmental demands is

good. However, empirical study and knowledge of sport parents’ coping skills and strategies

related to these demands remains limited. Early research by Kirk and colleagues (1997) and

6 Baxter-Jones and Maffuli (2003) reinforced the substantial financial demands of youth sport

7 on parents, affecting their personal, social, and broader family life choices. A series of three

8 studies conducted by Harwood and colleagues (Harwood \& Knight, 2009a, 2009b; Harwood,

9 Drew \& Knight, 2010) subsequently highlighted the range of stressors experienced by parents

10 of children involved in youth tennis and professional youth soccer academies. Beyond

11 competition stressors (see postulate 3), parents voiced several organizational and

12 developmental demands they faced in each of these settings.

Organizational demands included finance and time commitments, which instigated

sport-work role conflict, and also sport-family role conflict. This conflict incorporated

strained spousal relations and quality of social life and the negative effects of sibling

resentment and parental guilt due to the lack of attention afforded to the non-sport sibling.

which have also emerged as prominent organizational stressors (Harwood \& Knight, 2009a,

200b). Coaching behavior, club, and national sport federation processes also formed

prominent organizational stressors. For example, parents have consistently reported a lack of

communication and feedback from coaches, funding criteria and non-transparent selection

21 decisions, and a pressurizing talent development system. Organizational conflict also

extended to sport-school relations due to lack of school support when training and 


\section{EXPERTISE IN SPORT PARENTING}

Developmental demands encompassed issues affecting their child's overall sport and personal development. Within youth tennis (Harwood \& Knight, 2009b), developmental stressors included making appropriate decisions regarding coach, training and tournament programs, maintaining the value of education, and the persistent uncertainty of their child's future in the sport and the impact on their general life. Allied to this, parents reported concern over their child missing out on other hobbies and activities. The stress of uncertainty and lack of knowledge about the future also permeated the experience of football parents (Harwood et al., 2010). Parents constantly feared the release (i.e., deselection) of their child from football academies, struggled with lack of communication from coaches, and worried about how their child would manage sport and school pressures (i.e., exams). Such developmental stressors appear to be particularly pertinent during the later stages of children's sporting involvement, as children increasingly commit to sport and progress through the education system (Harwood \& Knight, 2009b).

Similar organizational and developmental concerns were also apparent in a study looking at how retirement (and the experiences parents had in sport prior to their child retiring) affected parents (Lally \& Kerr, 2008). Parents indicated their daughter's involvement in gymnastics had often put serious strain on their marital relationship and only on retirement had parents began to re-establish these relationships. Parents also disclosed lingering doubts and guilt regarding the decisions they had made. Specifically, parents expressed concerns related to the pain and injuries their child had experienced, their lack of development outside of sport, and seemingly abusive behavior they had encountered from coaches.

Although the relationship between parenting stress and parent-child interactions has not been studied within youth sport, literature from developmental psychology consistently indicates that parenting stress can influence parent-children interactions and the behaviors of 


\section{EXPERTISE IN SPORT PARENTING}

1 parents (Abidin, 1992; Belsky, 1984). For example, higher levels of parenting stress have

2 been associated with more punitive behaviors and harsher punishment from parents (Deater-

3 Deckard, 2004). As such, we might anticipate that the extent to which parents are able to

4 manage a range of stressors and cope with the demands they encounter in youth sport will

5 influence the extent to which parents offer appropriate support to their children.

6 In conclusion, we believe parents will face many organizational and developmental

7 demands with some more prominent at specific stages of their child's participation. When

8 parents manage these demands they strengthen their ability to help their child navigate

9 through the demands and uncertainties of sport. Therefore, sport parenting expertise requires

10 the development and application of various coping skills and strategies to manage these

11 diverse demands. In the absence of specific research into this area, we invite youth sport researchers to investigate this postulate and explore how, and to what extent, sport parents expertly cope with such demands.

\section{Postulate no. 6: Expert parents adapt their involvement and support to different} progress through sport, parents’ roles, experiences, demands, and responsibilities change. Parents themselves go through transitions (Lally \& Kerr, 2008; Wylleman \& Lavallee, 2004), and we believe an important component of parenting expertise is the extent to which parents are able to positively adapt their involvement in tandem with their children's sporting progressions and developmental needs. We hope we have already made a strong case for the factors contributing to sport parenting expertise. Nonetheless, there is a sound body of research that speaks to the need for parental adaptability through the stages of athlete development (Cóte 1999; Knight \& Holt, 2014; Lauer et al., 2010a, 2010b). Within the sampling stage, as highlighted in postulate 1, research reinforces that the most central forms 


\section{EXPERTISE IN SPORT PARENTING}

1 of parental involvement involve the provision of, and logistical commitment to, appropriate

2 sporting opportunities. However, in this early period, parents also focus on attitude, value,

3 and character development in their child, marking the beginning of their role as 'interpreter'

4 and decisions around sport parenting style (see postulates 2 and 3).

When children transition to the specializing stage and athletic involvement intensifies,

6 a transition in parental involvement is also required. In this stage, the demands placed upon

7 logistical provision increase as parents adapt to becoming managers of organizational and

8 relational issues as well as providing important emotional, motivational and esteem support

9 to their child around competitions (see postulates 3, 4 and 5). Their role as an effective

10 interpreter, role model, and educator is significant in this period as their child manages first

11 time challenges due to their physical development or performance improvements (see

12 Keegan, Spray, Harwood, and Lavallee, 2010).

The transition between specializing and investment stages can be marked by

14 uncertainty and anxiety for both child and parent (Harwood \& Knight, 2009b). Although

15 limited research has specifically targeted this transition, we believe this period of adaptation

16 may be the most difficult for parents. With the growing independence of their child, parents

17 are required to collaborate with their child on making balanced and informed decisions

18 regarding education that take into account the realistic prospects and demands of a potential

19 career in elite sport (see postulate 5; Lauer et al., 2010a). When a child progresses to this

20 investment stage, research suggests that elements of a parent's 'provider' role reduce and

21 coaches take on more expert support roles as parents transition into the background. Parents

22 of elite athletes have reported how negotiating this shifting role is stressful and challenging as

23 they are no longer close to the center of their child's athletic world (Jowett \& Timson-

24 Katchis, 2005). However, research has illustrated how parents can and should adapt to 


\section{EXPERTISE IN SPORT PARENTING}

1 continue to provide unconditional social support and a safe haven for their young adult as

2 they develop their independence and pursue their sporting and life goals (Côté, 1999). developmental research, there is a lack of evidence associated with parents’ experiences of adaptation and specifically how they cope with transitions between the different stages. Such within-career transition research for parents would make for a worthy contribution to the

9 literature and inform the veracity of this final postulate.

\section{Recommendations, Implications and Conclusions}

On appraising the content of these postulates, our hope is the interested researcher and practitioner can appreciate the multidimensional and developmental nature of sport parenting expertise. We also hope readers have gained a sense of the research gaps and opportunities that relate to each specific postulate. However, in closing this position paper, we feel it is important to synthesize some key messages from these postulates and reinforce some specific theoretical implications and opportunities for empirical study in this area as a whole. We also hope to draw out some potential caveats and critical areas for reflection relative to advancing this area of study. Finally, we will pose some applied implications for practitioners and organizations.

\section{Theoretical implications and further research avenues}

By critically reviewing relevant literature within our postulates, we perceive that sport parents face a consistent cycle of triangular responsibilities which revolve around managing and supporting the needs of their child, managing themselves and their well-being, and managing their interactions with the youth sport environment. In support of Henriksen et al., (2010), interactions at the ecological core and micro-level include coaches and those in the 


\section{EXPERTISE IN SPORT PARENTING}

1 child's immediate sporting network (e.g., other parents and peers), whereas interactions with

2 school teachers, club directors, or national federation staff represent increasingly macro-level

3 environmental exchanges. Notwithstanding financial and other less controllable constraints,

4 we believe all three of these responsibilities demand an extensive amount of knowledge and a

5 range of intrapersonal, interpersonal, and organizational skills that parents with greater

6 expertise will consistently demonstrate. Our theorizing about this triangular range of skills,

7 however, is certainly ahead of research support at this stage.

At an intrapersonal level, we would theorize that constructs such as parental

9 emotional intelligence (Gottman, Katz, \& Hooven, 1996), implicit beliefs (Dweck, 1999),

10 achievement goals (Duda \& Hom, 1993), parenting style (Sapieja et al., 2011), coping

11 (Nicholls \& Polman, 2007) and resilience (Fletcher \& Sarkar, 2013) represent domains that may help to inform the intrapersonal skill-set of sport parents. When supporting their child, we would consider parents with greater expertise to demonstrate higher levels of selfawareness and meta-emotion skills (Gottman et al., 1996), assisted by their incremental beliefs about learning, task/mastery goal orientation and an authoritative or autonomysupportive parenting style (see postulates $1,2 \& 3$ ). When engaging with the external environment and facing enduring sport-related stressors across an athlete’s career, we would also contend that such parents demonstrate higher levels of adaptive coping, with resilience being an asset we feel is particularly worthy of investigation (see postulates $5 \& 6$ ). We feel strongly that, when all of these factors begin to coalesce, positive psychosocial experiences

21 are likely for both child and parent, leading to improvements in skill development and performance. At present, there is little to no scientific research in sport that has considered emotional intelligence, coping, or resilience in parents and we invite researchers to question,

24 debate, and enhance knowledge in all of these aforementioned areas. 


\section{EXPERTISE IN SPORT PARENTING}

1

2 (i.e., listening, attending, empathy, giving constructive feedback), and more advanced skills

3 (e.g., effective questioning, negotiation, assertiveness, and confrontation) are salient qualities

4 that parents with greater expertise would differentially demonstrate in their interactions with

5 children and adults in youth sport contexts (see postulates 2 \& 4). The learning and

6 deployment of these person-centered skills may be highly dependent on the intrapersonal

7 characteristics noted above (e.g., emotional intelligence; Burleson et al., 1995). However, we

8 would contend that overall social support (Rees \& Hardy, 2000; Wolfenden \& Holt, 2005) is

9 more available to the child when these intrapersonal and interpersonal factors work together.

10 There is limited research in sport that has specifically studied parents' communication skills

11 with children and adults, and researchers are encouraged to access the family/communication studies literature where there is support for how person-centred parental communication in the home positively impacts on the social-cognitive skills of the child (Burleson et al., 1995). The deployment of interpersonal skills with other adults in youth sport in order to foster and manage relationships is without study to our knowledge. However, we believe these skills are important components of sport parent expertise alongside several organizational skills that help parents to effectively interact with the environment (see postulates $4,5 \& 6$ ). When empathizing with the personal and external demands placed on parents, organizational skills such as time management, collaboration, conflict resolution, persuasion/negotiation, networking, and even elements of organizational leadership (Fletcher \& Arnold, 2011) may be salient at different time points and stages in their child's sporting journey. Competitive youth sport environments are (by definition) competitive, and this extends to the skills of parents in terms of navigating the environment, pursuing resources, and ensuring the needs and interests of their child are appropriately met. We do not subscribe to the belief that sport parents should be passive beings who relinquish all control over their 


\section{EXPERTISE IN SPORT PARENTING}

1 child's sport program. Practitioners in youth sport recognize the reality is far different,

2 particularly when national federations, sports agents, sponsors, the media, and other parties

3 take an interest in their child-athlete. Parents should be proactively ready for this in order to

4 help their child who may still be in early to mid adolescence. In this respect, there is a sense

5 that sport parenting expertise extends to parents playing certain leadership roles to support

6 their child when interacting with such parties, as well as collaborating with other parents to

7 share resources and meet social needs.

The study of organizational psychology in sport has emerged over the last decade (see

9 Fletcher \& Wagstaff, 2009), but its application to sport parent roles remains in its infancy.

10 The organizational leadership role of performance directors in sport has been recently studied

11 (Fletcher \& Arnold, 2011), and we sense that at the 'sharper end' of high level youth sport there is something to be learned from how certain parents subtly, yet artfully, navigate the system in the best interests of their child. We believe that research that investigates the organizational skills and experiences of parents of successful, role-model performers may be valuable here (see postulate 6).

Gender, sport type and the notion of sport parenting expertise. Beyond these theoretical observations and recommendations for further study, we have reflected on additional gaps in the literature throughout the review process. Firstly, we appreciate there will not be one singular truth to expert sport parenting, because of the many different cultural and ethnic backgrounds reflected in the world of youth sport. Research in sport parenting is

21 almost exclusively dominated by Western culture, and it is important to investigate other cultures to determine how parenting expertise may be defined through different styles and practices of parents. Additionally, the modern family is becoming ever more varied and blended in global society in terms of its configuration, and it is important for researchers to 


\section{EXPERTISE IN SPORT PARENTING}

1 understand how specific components of expertise may differ according to the family structure

2 (see Harwood, Johnston \& Minniti, 2012).

Through the aforementioned postulates we have sought to offer an overall position on

sport parenting expertise and we anticipate that, at least at the broadest level, these postulates

would apply across different sports and genders. That said, it is important to recognize that some of the specific elements within each postulate might differ depending on parent or child gender (cf., Bois et al., 2009; Leff \& Hoyle, 1997; Stein et al., 1999). For example, it has been highlighted that mothers provide more positive comments than fathers at competitions

9 (e.g., Bowker et al., 2009; Holt et al., 2008), and that males might perceive more pressure 10 than females from their parents, particularly their fathers (e.g., Bois et al., 2009; Leff \& 11 Hoyle, 1997). Thus, it is feasible that there might be different expectations and requirements from female and male athletes, and certain postulates might be more or less pertinent for mothers or fathers.

Similarly, it is likely that certain elements of each postulate might be more or less relevant or necessary for parents whose children are involved in individual or team sports (e.g., tennis compared to football) and those sports where children specialize at an earlier or later age (e.g., gymnastics compared to rowing). To date, research specifically examining different types of sports is relatively limited (with researchers generally conducting studies focused within a specific sport). In fact, there is need for research into parents from a greater range of systems and sports. Tennis, football (soccer) and ice hockey tend to dominate the literature, and it is important to see other youth sports represented in our body of knowledge. The parenting literature in tennis, for example, has consistently highlighted the high financial and time demands placed on parents due to the individual nature of the sport (cf., Gould et al., 2006, 2008; Harwood \& Knight 2009a, 2009b; Lauer et al., 2010a, 2010b) and the dependency of the child on the parent for extensive transportation. This perhaps indicates that 


\section{EXPERTISE IN SPORT PARENTING}

1 postulate five might be particularly pertinent within certain individual sports, when compared

2 to more traditional team sports. Different types of individual and team sports may determine

3 the significance of postulates three and four with reference to the management of emotions

4 and relationships in the training and competition environment. The structure, nature and

5 culture of certain individual (e.g., head to head) and team sports can incite more intense, in

6 situ emotions than other sports. Likewise, even though team sports tend to necessitate more

7 frequent interactions between parents and their children, the intensive nature of certain

8 individual sports (e.g., gymnastics, swimming, tennis) may heighten the importance of

9 effective parent-parent and parent-coach relationships discussed in postulate four. In sum, it

10 is critical for further research to examine the appropriateness of our propositions across sports

11 and gender-dyads (e.g., mother-son, mother-daughter, father-son, father-daughter); and in so

12 doing offer insights into how certain intrapersonal, interpersonal and organizational skills

13 may be more requisite components of parenting expertise for certain sports or gender-dyads.

14 A final area that we consider important for further scholarly debate is the actual

15 notion of sport parenting expertise. In proposing a statement of sport parenting expertise and

16 identifying six underpinning components, we have aimed to illustrate the types of parental

17 behavior, practices, and participatory involvement that optimize children's sport experiences

18 and outcomes. However, it may be reasonable to argue that these postulates indicate

19 behaviors and practices that simply reflect the desirable expectations of "average” parenting.

20 Our interpretation of the current literature is that not all parents, particularly when they

21 initially become involved in competitive youth sport, possess the knowledge, skills, or understanding that underpins sport parenting expertise. Thus, in line with coaching expertise

23 literature, we believe that research examining: (a) the components of parenting expertise; (b)

24 how and when such expertise is developed, and (c) what support parents require to gain such

25 expertise, would be worthy avenues in advancing sport parenting. 


\section{EXPERTISE IN SPORT PARENTING}

\section{Applied implications for practitioners and organizations}

Parents form a consistent part of the fabric of youth sport, and we believe it is

3 incumbent upon practitioners, responsible clubs, and federations to help strengthen the

4 competencies and skills of sport parents such that a healthy sport experience and environment

5 is maintained. This paper highlights that sport parents require a high-degree of sport

6 parenting knowledge and certain cognitive, social, and emotional skills in the same way as

7 their children will benefit from such skills themselves in sport. Working for parents in sport

8 begins with an empathic awareness of the demands they face and an understanding of these

9 postulates of parenting expertise. Stage specific education and support provision to parents

10 through one-to-one work, workshops, online resources, and regular meetings will help

11 parents to gain more understanding, confidence, and expertise in their roles. Similarly,

12 working with coaches on relationship-management with parents, and with parents on

13 relationships with others should serve to ameliorate interpersonal skills amongst key parties

14 in an athlete’s social network (Jowett \& Timson-Katchis, 2005).

15 Conspicuous by its absence is the lack of published, field-based intervention research 16 specifically with sport parents (Harwood \& Swain, 2002; Smoll, Smith \& Cumming, 2007).

17 Our body of research is such that applied researchers, practitioners, and organizations have a

18 genuine opportunity to conduct proactive interventions that meet parents' education and

19 support needs, and thus enhance the strength of their expertise. In conclusion, by answering

20 the call of this special issue, we hope this article stimulates thinking on the development of

21 excellence and expertise in sport parents, and initiates action through scholarly research and applied practice. 


\section{EXPERTISE IN SPORT PARENTING}

2 Abidin, R. R. (1992). The determinants of parenting behavior. Journal of Clinical Child and Adolescent Psychology, 21, 407-412. doi:10.1207/s15374424 jccp2104_12

Arredondo, E. M., Elder, J. P., Ayala, G. X., Campbell, N., Baquero, B., \& Duerksen, S. (2006). Is parenting style related to children's healthy eating and physical activity in Latino families? Health Education Research, 21, 862-871. doi:/10.1093/her/cyl110

Babkes, M. L., \& Weiss, M. R. (1999). Parental influence on cognitive and affective responses in children's competitive soccer participation. Pediatric Exercise Science, $11,44-62$.

Baker, J., Côté, J., \& Abernethy, B. (2003). Sport specific training, deliberate practice and the development of expertise in team ball sports. Journal of Applied Sport Psychology,

Baker, J., Horton, S., Robertson-Wilson, J., \& Wall, M. (2003). Nurturing sport expertise: Factors influencing the development of elite athletes. Journal of Sports Science and Medicine, 2, 1-9.

Bailey, R., \& Morley, D. (2006). Towards a model of talent development in physical education. Sport, Education \& Society, 11, 211-230.doi:10.1080/13573320600813366

Baumrind, D. (1971). Current patterns of parental authority. Developmental Psychology, 4, 1103. doi:10.1037/h0030372

Baxter-Jones, A. D., \& Maffuli, N. (2003). Parental influence on sport participation in elite young athletes. The Journal of Sports Medicine and Physical Fitness, 43, 250-255.

Belsky, J. (1984). The determinants of parenting: A process model. Child Development, 55, 83-96. doi:10.2307/1129836 


\section{EXPERTISE IN SPORT PARENTING}

Benson, P. L., Leffert, N., Scales, P. C., \& Blyth, D. A. (1998). Beyond the "village” rhetoric: Creating healthy communities for children and adolescents. Applied Developmental Science, 2, 138-159.

1 Bloom, B. (1985). Developing talent in young people. New York, NY: Ballantine Books.

2 Bois, J. E., Lalanne, J., \& Delforge C. (2009). The influence of parenting practices and

3

4 parental presence on children's and adolescents' pre-competitive anxiety. Journal of Sports Sciences, 27, 995-1005. doi:10.1080/02640410903062001

Bowker, A., Boeknoven, B., Nolan, A., Bauhaus, S., Glover, P., Powell, T., \& Taylor, S. (2009). Naturalistic observations of spectator behavior at youth hockey games. The Sport Psychologist, 23, 301-316.

Bronfenbrenner, U. (1999). Environments in developmental perspective: Theoretical and operational models. In S.L. Friedman \& T.D Wachs (Eds.), Measuring environment across the life span: Emerging methods and concepts (pp. 3-28). Washington, DC: American Psychological Association Press.

Burleson, B.R., Delia, J.G., \& Applegate, J. L. (1995). The socialization of person-centered communication: Parents' contributions to their children's social-cognitive and communication skills . In M. A. Fitzpatrick \& A. L. Vangelisti (Eds.), Explaining family interactions (pp. $34-76$ ). Thousand Oaks, CA : Sage.

Camiré, M., Forneris, T., Trudel, P., \& Bernard, D., (2011). Strategies for helping coaches facilitate positive youth development through sport. Journal of Sport Psychology in Action, 2, 92-99. doi:10.1080/21520704.2011.584246

Côté, J. (1999). The influence of the family in the development of talent in sport. The Sport Psychologist, 13, 395- 417. 


\section{EXPERTISE IN SPORT PARENTING}

1 Côté, J., Baker, J., \& Abernethy, B. (2007). Practice and play in the development of sport expertise. In R. Eklund \& G. Tenenbaum (Eds.), Handbook of sport psychology, (pp. 184-202; $3^{\text {rd }}$ ed). Hoboken, NJ: Wiley.

Côté, J., \& Gilbert, W. (2009). An integrative definition of coaching effectiveness and expertise. International Journal of Sports Science and Coaching, 4, 307-323. doi:10.1260/ 174795409789623892

Côtè, J., \& Hay, J. (2002). Children’s involvement in sport: A developmental perspective. In J.M. Silva, \& D.E. Stevens (Eds.), Psychological foundations of sport (pp. 484-502). Boston, MA: Allyn and Bacon.

Côté, J., Lidor, R., and Hackfort, D. (2009). ISSP position stand: To sample or to specialize? Seven postulates about youth sport activities that lead to continued participation and elite performance. International Journal of Sport and Exercise Psychology, 9, 7-17. doi:10.1080/1612197X.2009.9671889

Darling, N., \& Steinberg, L. (1993). Parenting style in context: An integrative model. Psychological Bulletin, 113, 487-496. doi:10.1037/0033-2909.113.3.487

Deci, E. L., \& Ryan, R. M. (1985). Intrinsic motivation and self-determination in human behavior. New York: Plenum.

Deater-Deckard, K. (2004). Parenting Stress. New Haven, CT: Yale University Press.

Dorsch, T. E., Smith, A. L., \& McDonough, M. H. (2009). Parents’ perceptions of child-toparent socialization in organized youth sport. Journal of Sport \& Exercise Psychology, 31, 444-468.

Duda, J.L., \& Hom, M. (1993). Interdependencies between the perceived and self-reported goal orientations of young athletes and their parents. Pediatric Exercise Science, 5, $234-241$ 


\section{EXPERTISE IN SPORT PARENTING}

1 Dweck, C. S. (1999). Self theories: Their role in motivation, personality, and development. Philadelphia, PA: Psychology Press.

3 Dworkin, J.B., Larson, R., \& Hansen, D. (2003). Adolescents' accounts of growth experiences in youth activities. Journal of Youth and Adolescence, 32, 17-26.

5 Fletcher, D. and Arnold, R. (2011). A qualitative study of performance leadership and management in elite sport. Journal of Applied Sport Psychology, 23, 223-242. doi: $10.1080 / 10413200.2011 .55918$

Fletcher, D., \& Sarkar, M. (2013). A grounded theory of psychological resilience in Olympic champions. Psychology of Sport and Exercise, 13, 669-678.

Fletcher, D. and Wagstaff, C. R. D. (2009). Organizational psychology in elite sport: Its emergence, application and future. Psychology of Sport and Exercise, 10, 427-434. doi:10.1016/j.psychsport.2009.03.009

Fraser-Thomas, J., \& Côté, J. (2009). Understanding adolescents’ positive and negative developmental experiences in sport. The Sport Psychologist, 23, 3-23.

Fraser-Thomas, J., Côté, J., \& Deakin, J. (2005). Youth sport programs: An avenue to foster positive youth development. Physical Education and Sport Pedagogy, 10, 19-40. doi:10.1080=1740898042000334890

Fraser-Thomas, J., Côté, J., \& Deakin, J. (2008). Examining adolescent sport dropout and prolonged engagement from a developmental perspective. Journal of Applied Sport Psychology, 20, 318-333. doi:10.1080/10413200802163549

Fredricks, J. A., \& Eccles, J. S. (2004). Parental influences on youth involvement in sports. In M. R Weiss (Ed.), Developmental sport and exercise psychology: A lifespan perspective (pp. 145-164). Morgantown, WV: Fitness Information Technology. 


\section{EXPERTISE IN SPORT PARENTING}

1 Gottman, J.M., Katz, L.F., \& Hooven, C., (1996). Parental meta-emotion philosophy and the emotional life of families- Theoretical models and preliminary data. Journal of Family Psychology, 10, 243-268. doi:10.1037/0893-3200.10.3.243

Gould, D., Lauer, L., Rolo, C., Jannes, C., \& Pennisi, N. (2006). Understanding the role parents play in tennis success: A national survey of junior tennis coaches. British Journal of Sports Medicine, 40, 632-636. doi:10.1136/bjsm.2005.024927.

Gould, D., Lauer, L., Rolo, C., Jannes, C., \& Pennisi, N. (2008). The role of parents in tennis success: Focus group interviews with junior coaches. The Sport Psychologist, 22, 1837.

Grolnick, W.S. (2003). Psychology of parenting control: How well-meaning parenting backfires. Mahwah, NJ: Lawrence Erlbraum.

Gurland, S.T., \& Grolnick, W.S. (2005). Perceived threat, controlling parenting, and children’s achievement orientations. Motivation and Emotion, 29, 103-121. doi:10.1007/s11031-00507956-2

Hanton, S., \& Fletcher, D. (2005). Organizational stress in competitive sport: More than we bargained for? International Journal of Sport Psychology, 36, 273-283.

Harwood, C., Drew, A., Knight, C. J. (2010). Parental stressors in professional youth football academies: A qualitative investigation of specialising stage parents. Qualitative British tennis parents. Journal of Sports Sciences, 27, 339-351. doi:10.1080/ 02640410802603871 


\section{EXPERTISE IN SPORT PARENTING}

1 Harwood, C., \& Knight, C. (2009b). Stress in youth sport: A developmental investigation of tennis parents. Psychology of Sport and Exercise, 10, 447-456. doi:10.1016 /j.psychsport.2009.01.005

Harwood, C. G., \& Swain, A. B (2002). The development and activation of achievement goals within tennis II: A player, parent, and coach intervention. The Sport Psychologist, 16, 111-137.

Hellstedt, J. C. (1987). The coach/parent/athlete relationship. The Sport Psychologist, 1, 151160.

Hennessy, H., Hughes, S. O., Goldberg, J. P., Hyatt, R. R., \& Economos, C. D. (2010). Parent behavior and child weight status among a diverse group of underserved rural families. Appetite, 54, 369-377. doi:10.1016/j.appet.2010.01.004

Henriksen, K., Stambulova, N., \& Roessler, K. K. (2010). Holistic approach to athletic talent development environments: A successful sailing milieu. Psychology of Sport and Exercise, 11, 212-222. doi:10.1016/j.psychsport.2009.10.005

Holt, N. L. (2008). Positive youth development through sport. Abingdon, Oxon: Routledge.

Holt, N. L., \& Dunn, J. G. H. (2004). Toward a grounded theory of the psychosocial competencies and environmental conditions associated with soccer success. Journal of Applied Sport Psychology, 16, 199-219. doi:10.1080/10413200490437949

Holt, N. L., Tamminen, K. A., Black, D. E., Mandigo, J. L., \& Fox, K. R. (2009). Youth sport parenting styles and practices. Journal of Sport \& Exercise Psychology, 31, 37-59.

Holt, N. L., Tamminen, K. A., Black, D. E., Sehn, Z. L., \& Wall, M. P. (2008). Parental involvement in competitive youth sport settings. Psychology of Sport and Exercise, 9, 663-685. doi:10.1016/j.psychsport.2007.08.001

Horton, S., Baker, J. \& Deakin, J. (2005). Experts in action: A systematic observation of 5 national team coaches. International Journal of Sport Psychology, 36, 299-319. 


\section{EXPERTISE IN SPORT PARENTING}

1 Hoyle, R. H., \& Leff, S. S. (1997). The role of parental involvement in sport participation and performance. Adolescence, 32, 233-243.

3 Jago, R. P., Davison, K. K., Brockman, R., Page, A. S., Thompson, J. L., \& Fox, K. R. (2011). Parenting styles, parenting practices, and physical activity in 10- to 11-year olds. Preventive Medicine, 52, 44-47. doi:10.1016/j.ypmed.2010.11.001

Johnston, J., Harwood, C., \& Minniti, A. M. (2013). Positive youth development in swimming: Clarification and consensus of key psychosocial assets. Journal of Applied Sport Psychology, 25, 392-411. doi:10.1080/10413200.2012.747571

Jowett, S., \& Timson-Katchis, M. (2005). Social networks in sport: Parental influence on the coach-athlete relationship. The Sport Psychologist, 19, 267-287.

Juntumaa, B., Keskivaara, P., \& Punamäki, R. L. (2005). Parenting, achievement practices and satisfaction in ice hockey. Scandinavian Journal of Psychology, 46, 411-420. doi:10.1111/j.1467-9450.2005.00472.x

Keegan, R. J., Spray, C. M., Harwood, C. G., \& Lavallee, D. E. (2010). The 'motivational atmosphere' in youth sport: Coach, parent and peer influences on motivation in specializing sport participants. Journal of Applied Sport Psychology, 22, 87-104. doi:10.1080/10413200903421267.

Kidman, L., McKenzie, A., \& McKenzie, B. (1999). The nature and target of parents’ comments during youth sport competitions. Journal of Sport Behavior, 22, 54-68.

Kirk, D., Carlson, T., O’Connor, A., Burke, P., Davis, K., \& Glover, S. (1997). The economic impact on families of children's participation in junior sport. Australian Journal of Science and Medicine in Sport, 29, 27-33. doi:10.1080/1740898970020105

Knight, C. J., Boden, C. M., \& Holt, N. L. (2010). Junior tennis players’ preferences for parental behaviors at tournaments. Journal of Applied Sport Psychology, 22, 377-391. doi:10.1080 /10413200.2010.495324 


\section{EXPERTISE IN SPORT PARENTING}

1 Knight, C. J., \& Harwood, C. G. (2009). Parent-initiated coaching stress: A developmental study. International Journal of Sports Science and Coaching, 4, 545-565. doi:10.1260 /174795409790291448

Knight, C. J., \& Holt, N. L. (2013a). Parents' experiences at junior tennis tournaments in Western Australia. Sport, Exercise, and Performance Psychology, 2, 173-189. doi:10.1037 /a0031203

Knight, C. J., \& Holt, N. L. (2014). Parenting in youth tennis: Understanding and enhancing children’s experiences. Psychology of Sport and Exercise, 15, 155-164.

Knight, C. J., Neely, K. C., \& Holt, N. L. (2011). Parental behaviors in team sports: How do 69-92. female athletes want parents to behave? Journal of Applied Sport Psychology, 23, 7692. doi:10.1080 /10413200.2010.525589

Lally, P. S. \& Kerr, G. (2008). The effects of athlete retirement on parents. Journal of Applied Sport Psychology, 20, 42-56. doi:10.1080/10413200701788172

Lauer, L., Gould, D., Roman, N., \& Pierce, M. (2010a). Parental behaviors that affect junior tennis player development. Psychology of Sport and Exercise, 11, 487-496. doi:10.1016/j.psychsport.2010.06.008

Lauer, L., Gould, D., Roman, N., \& Pierce, M. (2010b). How parents influence junior tennis players’ development: Qualitative narratives. Journal of Clinical Sport Psychology, 4,

Leff, S. S., \& Hoyle, R. H. (1995). Young athlete’s perceptions of parental support and pressure. Journal of Youth and Adolescence, 24, 187-203. doi:10.1007/BF01537149 


\section{EXPERTISE IN SPORT PARENTING}

1 Martindale, R., Collins, D. \& Abraham, A. (2007) Effective talent development: The elite coach perspective in UK sport. Journal of Applied Sport Psychology, 19, 187-206. doi:10.1080 /10413200701188944

Maccoby, E. E., \& Martin, J. A. (1983). Socialization in the context of the family: Parentchild interaction. In P. H. Mussen (Series Ed.) \& E. M. Hetherington (Vol. Ed.), Handbook of child psychology: Vol. 4. Socialization, personality, and social development (4 $4^{\text {th }}$ ed., pp. 1-101). New York, NY: Wiley.

MacNamara, Á., Button, A. \& Collins, D. (2010a). The Role of Psychological Characteristics in Facilitating the Pathway to Elite Performance. Part 1: Identifying mental skills and behaviours. The Sport Psychologist. 24, 52-73.

MacNamara, Á., Button, A., \& Collins, D. (2010b). The role of psychological characteristics in facilitating the pathway to elite performance part 2: Examining environmental and stage-related differences in skills and behaviors. The Sport Psychologist, 24, 74-96.

Milevsky, A., Schlechter, M., Netter, S., \& Keehn, D. (2007). Maternal and paternal parenting styles in adolescents: Associations with self-esteem, depression and life satisfaction. Journal of Child and Family Studies, 16, 39-47. doi:10.1007/s10826-0069066-5

Nicholls, A. R., \& Polman, R. C. J. (2007). Coping in sport: A systematic review. Journal of Sports Sciences, 25, 11-31. doi:10.1080/02640410600630654

O’Byrne, K., Haddock, C., Poston, W. (2002). Parenting style and adolescent smoking. Journal of Adolescent Health, 30, 418-425.

Omli, J., \& LaVoi, N. M. (2009). Background anger in youth sport: A perfect storm? Journal of Sport Behavior, 32, 242-260. 


\section{EXPERTISE IN SPORT PARENTING}

1 Omli, J., \& Wiese-Bjornstal, D. M. (2011). Kids speak: Preferred parental behavior at youth sport events. Research Quarterly for Exercise and Sport, 82, 702-711. doi:10.1080 /02701367.2011.10599807

Omli, J., \& LaVoi, N. M. (2012). Emotional experiences of youth sport parents I: Anger. Journal of Applied Sport Psychology, 24, 10-25. doi:10.1080/10413200.2011.578102

6 Potrac, P. Jones, R., \& Armour, K. (2002). “It’s all about getting respect”: The coaching behaviors of an expert English soccer coach. Sport, Education \& Society, 7, 183-202. doi:10.1080/1357332022000018869

Rees, T., \& Hardy, L. (2000). An investigation of the social support experiences of high-level sport performers. The Sport Psychologist, 14, 327-347.

Sapieja, K. M., Dunn, J. G. H., \& Holt, N. L. (2011). Perfectionism and perceptions of parenting styles in male youth soccer. Journal of Sport \& Exercise Psychology, 33, 20-39.

Schmitz, K. H., Lytle, L. A., Phillips, G. A., Murray, D. M., Birnbaum, A. S., \& Kubik, M. Y. (2002). Psychosocial correlates of physical activity and sedentary leisure habits in young adolescents: The teens eating for energy and nutrition at school study. Preventive Medicine, 34, 266-278. doi:10.1006/pmed.2001.0982

Smoll, F. L., Smith, R. E., \& Cumming, S. P., (2007). Effects of coach and parent training on performance anxiety in young athletes: A systemic approach. Journal of Youth Development, 2, 0701FA002.

Smoll, F. L., Cumming, S. P., \& Smith, R. E., (2011). Enhancing coach-parent relationships in youth sports: Increasing harmony and minimizing hassle. International Journal of Sports Science and Coaching, 6, 13-26. doi:10.1260/1747-9541.6.1.13

Soberlak, P., \& Côté, J. (2003). The developmental activities of elite ice hockey players. Journal of Applied Sport Psychology, 15, 41-49. doi:10.1080/10413200305401 


\section{EXPERTISE IN SPORT PARENTING}

1 Spera, C. (2006). Adolescents' perceptions of goals, practices, and styles in relation to their motivation and achievement. The Journal of Early Adolescence, 26, 456-490. doi:10.1177/0272431606291940

Stein, G. L., Raedeke, T. D. \& Glenn, S. D. (1999). Children’s perceptions of parent sport involvement: It's not how much, but to what degree that's important. Journal of Sport Behavior, 22, 591-601

Strachan, L., Côté, J., \& Deakin, J. (2009). “Specializers” versus “Samplers” in youth sport: Comparing experiences and outcomes. The Sport Psychologist, 23, 77-92.

Tucker, Derelian, \& Rouner, 1997. Building the case: Position papers, backgrounders, fact sheets, and biographical sketches. In Public relations writing: An issue-driven behavioral approach (pp.79-85). Upper Saddle River, NJ: Prentice Hall.

Ullrich-French, S., \& Smith, A. L. (2006). Perceptions of relationships with parents and peers in sport: Independent and combined prediction of motivational outcomes. Psychology of Sport and Exercise, 7, 193-214.

Vella, S. A., Oades, L. G., \& Crowe, T. P. (2011). The role of the coach in facilitating positive youth development: moving from theory to practice. Journal of Applied Sport Psychology, 23, 33- 49. doi:10.1080/10413200.2010.511423

Wiersma, L. D., \& Fifer, A. M. (2008). “The schedule has been tough but we think it’s worth it”: The joys, challenges, and recommendations of youth sport parents. Journal of Leisure Research, 40, 505-530.

Wolfenden, L. E., \& Holt, N. L. (2005). Talent development in elite junior tennis: Perceptions of players, parents, and coaches. Journal of Applied Sport Psychology, 17, 108-126. doi:10.1080/10413200590932416

Woodman, T., \& Hardy, L. (2001). A case study of organizational stress in sport. Journal of Applied Sport Psychology, 13, 207-238. doi:10.1080/104132001753149892 


\section{EXPERTISE IN SPORT PARENTING}

1 Wuerth, S., Lee. M. J., \& Alfermann, D. (2004). Parental involvement and athletes' career in youth sport. Psychology of Sport and Exercise, 5, 21-33. doi:10.1016/S14690292(02)00047-X

Wylleman, P., \& Lavallee, D. (2004). A developmental perspective on transitions faced by athletes. In M. Weiss (Ed.), Developmental sport and exercise psychology: A lifespan perspective, (pp.507-527). Morgantown, WV: Fitness Information Technology. 